\title{
IS KERALA BECOMING A KNOWLEDGE SOCIETY? \\ EVIDENCE FROM THE SCIENTIFIC COMMUNITY
}

\section{R. Sooryamoorthy *}

\section{Wesley Shrum \#}

\begin{abstract}
When knowledge becomes the key for progress and development its generation assumes great significance. Who generates it and how it is done become important issues, and particularly so in developing societies. We attempt to understand both the players and the system of knowledge generation using data from a longitudinal study of 404 scientists in Kerala collected in 1994 and 2000. The analysis focuses on changes occurring during this period in the personal characteristics of the researchers, their professional activities, and their productivity.
\end{abstract}

Keywords: Knowledge Society, Science and Transformation.

* Senior Lecturer, Sociology Programme, Faculty of Human Sciences, University of Natal, Durban 4041, South Africa. Email: sooryamoorthyr@nu.ac.za

\# Professor and Director of Graduate Studies, Department of Sociology, Louisiana State University, Baton Rouge, LA 70803, USA. Email: shrum@1su.edu 


\section{IS KERALA BECOMING A KNOWLEDGE SOCIETY? \\ EVIDENCE FROM THE SCIENTIFIC COMMUNITY}

\section{Introduction}

Knowledge has become the buzzword in modern societies, dominating capital and labour. A modern society was, until recently, perceived in terms of property and labour, while capitalist society was viewed as society of owners and non-owners. Soon it became a labouring society, and now it is forming into a knowledge society (Stehr 2001: 495). The link between knowledge and development is more and more pronounced. Knowledge is the ability to transform our resources to our advantage and it has become the most important factor determining our standard of living, more than land, tools, or labour (World Bank 1998-99: 16). Today most technologically advanced economies are knowledge-based. Not only do they generate new wealth from their innovations, but they create vast numbers of knowledge-related jobs (Ibid). As a consequence, societies are now transformed into what many theorists have viewed as true knowledge societies (Bell 1973; Drucker 1969; Lane 1966). ${ }^{1}$ The emergence of knowledge societies, however, is not a spontaneous event but a gradual process in which societies acquire new traits and features. Knowledge has become more fundamental and strategic for most spheres of life and it is modifying or even replacing the factors that have been constitutive of social action (Stehr 2001: 496).

India possesses one of the five largest scientific communities in the world and accounts for about half of the scientific production of the developing countries as a whole (Gaillard et al 1997: 41). The developing countries together represent only seven per cent of the world's mainstream scientific output, of which close to 80 per cent is produced in 
Asia. India's mainstream production has increased at about the same pace as the total world output during 1985-92.

Given that knowledge is becoming the basis of growth and development, this paper examines the institutional settings of knowledge creation in a small but widely-acclaimed state of Kerala in southwestern India. Even today it is believed to be a model of development though the initial euphoria about its achievements and credentials in several socio, economic and demographic spheres is on the wane. The setting has significance for two reasons. First, the state has initiated a number of programmes, following the footprints of many other southern states like Karnataka, Andhra Pradesh and Tamil Nadu, in order to chart a new path for its development by taking advantage of the demand for information technology (IT) the world over. The new IT policy document makes it clear that the growth of Kerala in the coming years will be increasingly driven by the knowledge and service-based sectors where information flow will be a key determinant factor of success (GOK 2001: 5). ${ }^{2}$

When knowledge is the key for progress and development, its generation and the structures that facilitate or hinder the process become important. Added to this is the socio-economic ambience that stems from the process of globalisation. Scientific and technical knowledge produces incremental capacities for social and economic action or an increase in the ability to 'how-to-do-it' (Stehr 2001: 498). This study focuses on the people who are involved in the generation of knowledge over a period of time within Kerala. Based on a study first conducted in 1994, then repeated in 2000 in the teaching and research sectors, we trace the changes that have occurred at both the individual and system levels and looks at how the transformation affects the research system in Kerala. 


\section{Methodology}

Kerala was one of three locations, along with Kenya and Ghana, in which the original field survey of scientists was conducted in 1994. A team of three interviewers spent five weeks travelling through the state conducting approximately 100 interviews in universities, research institutes, and a few NGOs. The primary basis for selecting organisations in the academic and government research sectors was publication productivity. The individuals interviewed were all involved in some aspect of research on agricultural, environmental, and natural resource issues. First, a preliminary search of 79 databases was carried out using the DIALOG system. ${ }^{3}$ After discarding sources in irrelevant fields and those with few hits, 17 international databases were searched for the 1992-3 period. This allowed the preliminary identification of a group of organisations and scientists before fieldwork began. The sample was stratified by sector, focusing primarily on university departments and national research institutes, interviewing approximately three individuals in each institution. Fifty seven per cent of our 1994-respondents belonged to national institutes, 31 per cent to universities, and 12 per cent to NGOs. In terms of organisations, these individuals represent 49 organisations in three sectors, including 22 government institutes, 20 university departments and 7 NGOs. Obtaining the permission and cooperation from the director of each organisation, we targeted mid-career researchers. We sought to divide our interviews between those whose names appeared in the international databases and those whose did not. A special effort was made to interview women researchers. ${ }^{4}$

The second set of respondents was contacted during three months beginning from June in 2000. The 1994 survey sought to be relatively comprehensive in its coverage of agricultural, environmental, and natural resource-related research institutions of the state, but because of time and cost constraints, relatively few individuals could be interviewed in each. In 2000 we determined to make every effort to increase the sample size. Hence, the 
2000 survey sought comprehensiveness in the number of individual scientists interviewed within each university department or research institute, with less coverage of the full range of organizations in 1994. The respondents were drawn from the main central and state government research organizations in the area of Thiruvananthapuram as well as scientific departments of the University of Kerala and the College of Agriculture at Vellayani. The focus, as in 1994, was on fields of specialisation in agriculture, biology, biochemistry, geology, mathematics, physics and social sciences. Thus we have a total of 404 respondents (101 from 1994 and 303 from 2000).

This paper looks at the transformation of the research community from 1994 to 2000 . In the tables that follow, we examine the realms of personal and academic background, professional life, productivity and research facilities. The 2000 survey contained a variety of new questions on the Internet, a subject that was only beginning to capture the attention of the Malayali research community in 1994. Therefore, this paper focuses on changes in the scientific community with items that appear in both surveys. The survey instrument included both structured and unstructured sections on the major dimensions of professional research activities, international and national organisational contacts, frequency of discussions with various groups, supervisory roles and local contacts, professional memberships and activities, self-reported productivity, attitudes on agricultural and environmental issues, and the needs of the research system.

\section{Background Data}

In the sample 37 per cent (150 respondents) were women (36.6 per cent in 1994 and 37.3 per cent in 2000). The even distribution indicates that there is no significant change in gender composition between the two time periods. Although the ratio of women to men in 
Kerala is in favour of women (1058: 1000), it is not reflected in the professional positions of women in the chosen institutions of higher learning and research. This gender imbalance in the academic hierarchy has been reported in a recent empirical study (Kumar 2001). In the mean age of the respondents there is a statistically significant difference of four years, indicating that the research community is aging (Table 1). Father's occupation, which gives an indication to the socio-economic background of the respondents, shows some significant changes between the two time periods. More and more children of civil servants are being attracted to the field of research and teaching. In 1994 only 13.7 per cent of scientists were children of civil servants, while in 2000 this figure had risen to 43 per cent. At the same time, as evident from the data for 2000, farm origins had declined by nearly 10 percentage points. This difference is found to be statistically significant when tested with Chi-square (Table 1). There are also fewer children of parents who are in the profession of medical/nurse in the 2000 data. Single respondents were four times higher in the earlier time period, probably indicating more experienced personnel in the present research and teaching systems of Kerala. This finding is consistent with the data on age in which the mean difference is notably higher for the second set of data.

[Table 1 about here.]

In the recent time period, partners of the respondents are more likely to be civil servants, or in the educational or medical sectors. The increase in teaching spouses owes primarily to the fact that men are likely to have wives in this sector. It implies that women respondents who are scientists, researchers and professors do not prefer teachers or those in allied fields as their husbands. In the present hierarchy of occupations in the state, teachers in schools fall below scientists, researchers and professors. In Kerala, women are generally encouraged to marry husbands with higher status occupations including educational qualifications. In accordance with the preference 40.5 per cent of women in 
the second survey have husbands who are civil servants, that is, regular and permanent positions in the governmental sector, as against 19 per cent wives for men respondents.

To further substantiate this argument, fewer women (only 5.4 per cent in 2000) have husbands who are in business or are working as merchants or shopkeepers.

Parenthetically it may be noted that men too do not prefer women in such occupations (the percentage of wives in the said occupations is less than one per cent). Employed men like scientists, researchers and professors also opt for partners in the regular, secured positions that bring in a steady income, cementing their positions firmly in the higher strata of the society. The percentage of housewives, i.e., who are not gainfully employed, registers a drop from 33.in 1994 to 26 in 2000 indicating that more employed men are choosing employed women as their life partners.

In both sets of data, over three quarters (77.2) of respondents possessed the Ph.D as their highest degree, but this indicates no advancement in the present system in terms of educational qualifications. There is even a drop of two percentage points in Master's level qualification, with the difference being qualifications such as M.Phil. However, this difference is small. In terms of educational credentials, the research capacity of Kerala has not improved since 1994.

As for the year of obtaining the highest degree such as M.A, M.Phil or Ph.D, the two sample means show significant difference when it was t-tested. It does not make much sense as there are several other variables that might intervene here. In view of the present rate and the extent of unemployment, the year of obtaining a position varies. ${ }^{5}$ This reflects the difficulty of finding employment as soon as one obtains qualifications for the post. It is also common to undertake some work for a higher degree (such as M.Phil or Ph.D.) after one has already taken employment - a prerequisite to climb the career ladder. For a majority, this practice of acquiring higher degrees while employed is for promotion within 
the organization and owes little to academic interests. It is quite evident among the teaching community — not only in Kerala but in many other states as well— that there are professors who undertake their Ph.D. study while close to retirement, as this is essential for promotions to higher levels. At the time of data collection in 1994, such degrees were not essential for even research positions in Kerala. Now higher qualifications like Ph.D are common because there is a sufficient supply of eligible candidates in the labour market. Although these qualifications are not mandatory even today, preference is given to candidates who possess higher qualifications.

Most respondents (over $90 \%$ in both years) do not have any degree from any developed countries. For those that do, most were obtained from the US, the UK and other parts of Europe (with a slight predominance from the US in the respondents in 2000). However, the difference between the two data sets is not statistically significant. Among those who obtained higher education in developed countries the average number of years spent outside the country was actually greater in 1994 than in 2000, indicating that Malayali scientists have, if anything, become less cosmopolitan over time. Though statistically insignificant, this indicates that fewer scientists in the Kerala research system have the opportunity for education outside the country. It seems clear that in the competitive environment, opportunities in the form of fellowships and study grants have not improved during the time period of the study — if anything they are shrinking.

\section{Professional Activities}

For those in the research sector the most significant role partners within the employing organization are other scientists and engineers, technicians and field workers, and other non-technical staff. The first six rows of Table 2 may indicate a general reduction in 
supervisory and collaborative relationships over time for intra-organizational relations. While there is a small difference in the number of professionals supervised, the number of technicians, fieldworkers, and non-technical staff has declined. The reduction in intraorganizational relationships is shown most clearly in rows 3 through 6 of Table 2, based on a series of questions on the number of individuals of various types within his/her own organization with whom the respondent works closely. We interpret these items as indicators of collaboration within the organization or academic department of the respondents. Clearly, the number of collaborators is lower in 2000 than it was in 1994. For scientific collaborators, as row 4 of Table 2 shows, the reduction is remarkable ( 8.63 to 3.23), a drop of nearly two-thirds. There are significant reductions as well in the number of technical and non-technical collaborators at less than professional rank (rows 56). If this is viewed as a measure of the extent to which researchers discuss research problems with other professionals, and the extent to which they are assisted in their research by non-professionals, then the reduction in research capacity is indeed puzzling, if not disturbing.

[Table 2 about here.]

Since 1920, when the Indian Botanical Association was formed, the number of professional scientific associations in India has increased. By 1940 there were about 17 such professional associations in the country (Krishna 1997: 239). ${ }^{6}$ Membership in such associations can facilitate the exchange of ideas and communication among scientific professionals and help keep them abreast of developments in their research fields. A large majority (over 80 per cent) of our respondents in both time periods reported membership in professional associations with only a minor change. ${ }^{7}$ Sometimes a keen interest in the discipline and specialisation motivates a scientist to become involved in professional organisations. Active involvement in an association and contributions to it increases the 
chance of rising to positions of responsibility. Such positions also indicate expertise and reputation as a researcher, factors that weigh heavily in the selection of persons for responsible positions in associations. As indicated in row 8 of Table 2, fewer than half were officers of such organizations and this percentage fell slightly in 2000 .

India produces more than half of the scientific journals published in the Third World. In the area of science and technology alone there are 1,500 journals published in India (Krishnan \& Viswanathan 1987, as quoted in Krishna 1997: 255). Scientific professionals may be involved in the publication process in various ways, including the editorial and peer-review activities of journals. This typically occurs once they have an established standing in their own field of research. Such an acceptance and recognition can be achieved only after years of research in a specific area of interest. Peer review is intended to control the quality of the contributions in the discipline, by collegial review of published problems and techniques. As indicated in row 9 of Table 2, slightly fewer than one-third of our respondents had, during the past five years, served on the editorial boards of professional journals. The trends in these positional variables for professional associations and journals do not indicate an improving condition for Kerala research system.

The policy roles of these individuals have improved significantly, however. A majority of respondents in 2000 reported activity on government committees or advisory groups, both bodies that play a part in the formulation of policies, which represents more than double the percentage in 1994. There was also a significant increase in consulting, from about half of the scientists in 1994 consultancy to nearly two-thirds in 2000 . Since their roles as advisors extension services and NGOs did not change (rows 12 and 13 of Table 2), we can say that Malayali scientists are engaging more with governmental and international agencies than in the recent past. This is not because of any decrease in the 
number of NGOs in the state since 1994, or the number of opportunities. ${ }^{8}$ But such services are often rendered voluntarily rather than for a charge. Consultancy services to NGOs and taking part in advisory roles in NGOs are not as lucrative as consulting work for governmental and international agencies.

Finally, data participation in training courses and the days away from the organisation for professional activities during the last five years do not augur well for the scientific community. The percentage of the respondents who had gone for any professional course or training registered a negligible change in 2000 (row 14, Table 2). Further, the average number of days the respondents spent away from the organisation for professional activities had declined considerably (row 17).

\section{Research and Productivity}

The expenditure of India on research and development, in terms of its proportion to the GNP, increased after 1975. This is conspicuous when it is compared with the proportion among other developing countries. But since the nineties the trend is reversed. $R \& D$ funding in India fell from 0.92 per cent of the GNP in 1990 to 0.70 per cent in 2000 (Krishna, 2002: 10). This may be compared with the figures of two to three per cent for the industrialised countries and 1.5 to 2.5 per cent for East Asia. As indicated by the Institute for Scientific Information (ISI), a widely used bibliometric data source, ten countries produce more than 80 per cent of international scientific literature. ${ }^{9}$ The output of research papers produced varies from country to country. Developed countries such as the USA, the UK, Japan, Germany, France, Canada and the Netherlands accounted for a range of 1.68 per cent to 36.67 per cent of the total world output during 1981-5 (Braun et al, quoted in Krishna 1997: 253). Developing countries such as Brazil, Egypt, Nigeria, 
Kenya, Thailand and Algeria range from 0.37 to 0.01 per cent. Among them, all except India are the members of the industrialised world. India, though a developing nation, falls somewhere in the middle with an output of 2.68 per cent during the said period. India has maintained its eighth place among publishing nations since the beginning of the seventies (Gaillard et al 1997: 43), above Italy, Australia, the Netherlands, Sweden and other European countries. It accounts for about 64 per cent of the total scientific output of the Third World comes from India (Ibid).

At the individual level as well, the productivity of scientists is measured on the basis of their scientific output. This can be assessed in terms of the research projects conducted or directed, contributions to national and international journals, research papers in edited volumes, and the production of monographs, reports and bulletins. Not only written output, but contributions to national and international conferences are an expression of one's productivity. As Table 3 indicates, our respondents report working an average of fifty hours a week, slightly fewer in 2000 than in 1994. However, the time investment in research is virtually the same in both time periods. The number of research projects in which the respondents were involved and the number of projects directed is another indicator of research activity. Respondents reported significantly more research projects in 2000 than in 1994, by a margin of 7.2 to 3.8 (row 3). However, part of these difference is accounted for by a greater range of responses in 2000 (from 16 in 1994 to 60 in 2000).

[Table 3 about here.]

The survey in both years contained a series of ten "written output" questions asking respondents to report their own productivity within the past five years. The most salient items pertain to articles in both foreign and national journals. We use self-reported publication data because of the absence of good bibliometric sources that include India. Publications are highly relevant for researchers in developing countries and they generally 
have little difficulty in remembering them. However, there is no further check on the accuracy of these self-reported publications. ${ }^{10}$

Table 3 shows little change in the primary types of research output. The contributions of the respondents to national and international (foreign) journals, edited volumes, the production of monographs, reports and bulletins do not show positive signs of change between the two time periods. Compared to 1994, self-reported contributions to foreign journals and national journals have declined. While there is a minor increase in the production of reports and contributions to edited titles, this is negligible. ${ }^{11}$ Such outputs are not treated equally with contributions in peer-reviewed journals. In most cases, reports and monographs may be converted into publishable forms in journals after considerable intellectual input is added. Likewise, the present level of participation in national and international conferences, meetings, workshops and seminars is not encouraging for the growth of research activities in the state. The rate of presentation of papers at international meetings has dwindled in recent years, while there is a positive change in the case of national meetings. These changes are not statistically significant.

\section{Conclusion}

This study examines scientists in Kerala over the period from 1994 to 2000, focusing on stability and change in the personal characteristics, professional activities and output. In terms of the composition of the research system, some transformation is evident, including the aging of the Malayali scientific community and the class background of these professionals. Further, research and teaching have become the preferred professions of the wards of the middle class parents in the state. This class character is maintained and reinforced in the choice of life partners. 
In terms of positive changes in the system, we found increased participation in policymaking bodies, a welcome trend that may pave the way for the integration of scientific knowledge in programmes and policies that affect the society. Further, there is some indication of an increase in the number of research projects. However, we are unsure whether the interpretation of this particular shift should be positive, and find little else to suggest the occurrence of improvements in the scientific system. Most characteristics examined showed little change, including such important indicators as the proportion of scientists with doctoral degrees and the relative absence of professional training abroad. In comparison with the 1994-respondents, the amount of time dedicated to research has declined. While the number of reported research projects has increased, the number of contributions of the respondents to national and international journals has actually declined in recent years, as well as participation in national and international meetings. The slight decrease in participation on the editorial boards of professional journals may also be a matter of concern.

One of our most puzzling findings is the reduction in the magnitude of interaction and intellectual exchange, indicated in our data by the number of collaborators within the local organization. Does this indicate that the scientists, researchers and professors in the state are confining themselves to their own academic islands or working on private projects, with declining interaction with the scientific fraternity? Perhaps the feeling for working closely with those in one's own organization also involves the competencies of these colleagues, who can be sought for clarifying thoughts and establishing productive research directions. The availability of such people may be a factor enhancing or reducing collaborative relationships among the researchers and teachers within an organization.

This pattern may be read in the context of the increase in consultancies, since such work is accomplished without subsequent published output. The low pay of many 
teachers and scientists and lack of encouragement accorded to these activities may be reducing interest in research. Other data (not shown) indicate a substantial increase in concern about the conditions for research, particularly in the matter of salaries. The organizational approach to reward and recognition has a significant impact on commitment of the scientific community to rigorous research activities. Though the current research scenario in Kerala may be better than that in some northern states of India, individuals who are dedicated, considering research as a tapasya, are few and in need of encouragement (Harikumar 2002: 4). ${ }^{12}$

In this respect the current work suggests problems in the research system as it exists in India as a whole. India is the third largest in the world in terms of human resources in science and technology (Krishna 1997: 263). The feeling that the system is now facing a crisis is strengthening. Partly, the research system is unable to attract the best talent. Prospective students are wooed by career-oriented disciplines such as management, administration, engineering and IT, while science does not appeal strongly enough to the talented (Krishna, 2002:10). Our results show that there is little improvement and much cause for concern regarding the state of the research system in Kerala.

\section{Notes}

The authors gratefully acknowledge the suggestions of the anonymous reviewers and the editor on the earlier version of this paper. Data from 1994 were collected under a grant from RAWOO, the Dutch Advisory Council for Scientific Research for Development Problems. Data from 2000 were collected under a grant from the U.S. National Science Foundation program in Information Technology Research.

1. The term 'knowledge society' came into being in the sixties. Robert Lane used it for the first time and Peter Drucker employed it very specifically. Daniel Bell, too, made use of this concept very widely in the 1970 s.

2. The preamble of the IT Industry Policy of the Government of Kerala states that it will evolve a strategy to harness the opportunities offered by Information Technology for the comprehensive social and economic development of the state. This strategy is to serve as a primary instrument for facilitating Kerala's emergence as a leading knowledge society in the region. The Government of 
India, too, in its IT Action Plan, makes it clear that IT is an agent of transformation of every facet of human life that will bring about a knowledge-based society in the twenty-first century.

3. DIALOG is the database of DIALOG Corporation in the US.

4. A standard response rate is difficult to calculate owing to the method used to obtain the interviews. In 1994 we sought to conduct interviews at most of the significant government research organisations in the state and at all university departments with significant agricultural or environmental research. One difference between the 1994 study and the 2000 study was the inclusion of a small number of NGO respondents in the former.

5. There were 4.186 million unemployed people registered in the Employment Exchanges of Kerala in 2000. Among them about 75 per cent have educational qualifications of school final and above. More than half (55.27) of these are women.

6. There were also societies and organisations of this kind before 1920. They included the Aligarh Scientific Society (1864), Bihar Scientific Society (1868), Punjab Science Institute (1886), the Dawn Society (1904), Indian Science Congress Association (1914), and the Association of Scientific and Industrial Organisation (1904). However, the Indian Botanical Association marked the professionalisation of science in India (Krishna, 1997, p.275).

7. Professional activities refer to a period of five years before the data was collected in 1994 and 2000.

8. In fact the number of NGOs is growing every year. A rough estimate shows that there is at least one NGO in every panchayat in Kerala. There are 991 panchayats in the state.

9. Gaillard et al (1997) notes that international scientific databases are highly selective and bibliometric studies based on this data represent only a small proportion of the world's science. This applies to those compiled by the Institute for Scientific Information, though this is the most widely used bibliographical database providing information on various countries. See also Frame et al (1977), Garfield (1983), Frame (1985), Moravcsik (1985), and Arvanitis and Gaillard (1992).

10. One objection to using self-reports is that they are based on memory, but the alternative is to use C.V.s, which are often unavailable and outdated. Moreover, there is frequently no means of reproducing them.

11. The history of India in this respect is interesting. For instance, Krishna (1997) notes that during 1836-95 India could publish only 18 papers in the journal of the Asiatic Society. But within the next 25 years Indian output was 350 papers.

12. This was the observation made by the famous scientist Prof. Jayanth Vishnu Narlikar in a recent interview. See Harikumar, 2002, p.4. 


\section{References}

Arvanitis, R, and J. Gaillard. 1992. (eds.). Science indicators for developing countries. Paris: ORSTOM, Colloques et Seminaires.

Bell, Daniel. 1973. The coming of post-industrial society: A venture in social forecasting. New York: Basic Books.

Drucker, Peter. 1969. The age of discontinuity: guidelines to our changing society. New York: Harper and Row.

Eisemon, T.O. 1982. The science profession in the third world: studies from India and Kenya. New York: Praeger.

Eisemon, T.O. , and C.H. Davis. 1992. "Universities and scientific research capacity." Journal of asian and african studies. 27(1/2):68-93.

Frame, D.J. 1985. "Problems in the use of literature-based S \& T indicators in developing countries." in H.Morita-Lou (ed.). Science and technology indicators for development (117-122). Boulder, CO: Westview.

Frame, D.J., F.Narin, and M.P.Carpenter. 1977. "The distribution of world science", Social studies of science, 7 (4):501-16.

Gaillard, Jacques, V.V. Krishna, and Roland Waast. 1997. "Introduction: Scientific Communities in the Developing World." in Jacques Gaillard, V.V. Krishna, and Roland Waast (eds.). Scientific communities in the developing world (11-47), New Delhi: Sage Publications.

Gibbons, Michael, Camille Limoges, Helga Nowotny, Simon Schwartzman, Peter Scott, and Martin Trow. 1995. The new production of knowledge. New Delhi: Sage Publications.

GOK. 2001. Information technology: Policy document. Thiruvananthapuram: Department of Public Relations, Government of Kerala.

Garfield, E. 1983. "Mapping science in the Third World", Science and public policy, 10(3): 112-27.

Harikumar, M.S. 2002. "Avashyamundu, sasthranjare" (Mal). Pp. 4 in Mathrubhumi. Trivandrum.

Krishna, V.V. 1997. "A portrait of the scientific community in India: historical growth and contemporary problems." In Jacques Gaillard, V.V. Krishna, and Roland Waast (eds.). Scientific communities in the developing world (236-80), New Delhi: Sage Publications.

—. 2002. "The S \& T policy." Pp. 10 in The Hindu. Thiruvananthapuram.

Kumar, Neelam. 2001. "Gender and stratification in science: An empirical study in the Indian setting", Indian journal of gender studies, 8(1): 51-67.

Lane, Robert E. 1966. "The decline of politics and ideology in a knowledgeable society", American sociological review, 31 (5):649-62.

Moravcsik, M.J. 1985. 'Strengthening the coverage of Third World science.' Oregon: International Task Force for Assessing the Scientific Output from the Third World,Eugene.

Parayil, Govindan, and Wesley Shrum. 1996. "Non-governmental research organisations in Kerala", Science, technology and development, 14(1): 122-32.

Shrum, Wesley Monroe. 1996. "Research capacity for sustainable development: Report of a field study in Ghana, Kenya and Kerala (India)." The Hague: Rawoo. 
Stehr, Nico. 2001. "Modern societies as knowledge societies." in George Ritzer and Barry Smart (eds.). Handbook of social theory (494-508), London: Sage Publications.

World Bank. 1998-99. "Knowledge for development." New York: The World Bank. 
Table 1

Characteristics of Respondents

\begin{tabular}{|c|c|c|c|c|}
\hline No. & Variable & 1994 & 2000 & $N$ \\
\hline 1 & Percentage Male & 63.4 & 62.7 & 404 \\
\hline 2 & Percentage Female & 36.6 & 37.3 & 404 \\
\hline 3 & Age $* * * \mathrm{~b}$ & 43.0 & 47.04 & 404 \\
\hline \multirow[t]{8}{*}{4} & Father's occupation $* * *$ a & & & 397 \\
\hline & Farmer/Peasant & 33.7 & 23.2 & \\
\hline & Teacher/Education & 11.6 & 12.9 & \\
\hline & Civil Servant & 13.7 & 43.0 & \\
\hline & Medical/Nurse & 5.3 & 1.7 & \\
\hline & Researcher/Professor/Scientist & 3.2 & 3.6 & \\
\hline & Business/Merchant/Shopkeeper & 11.6 & 8.9 & \\
\hline & Others & 21.1 & 6.6 & \\
\hline \multirow[t]{4}{*}{5} & Marital Status** a & & & 404 \\
\hline & Single & 8.9 & 2.0 & \\
\hline & Married & 90.1 & 97.4 & \\
\hline & Widowed & 1.0 & 0.7 & \\
\hline \multirow[t]{10}{*}{6} & Spouse's Occupation $* * *$ a & & & 386 \\
\hline & Farmer/Peasant & 0.0 & 0.7 & \\
\hline & Teacher/Education & 6.6 & 10.2 & \\
\hline & Civil Servant & 8.8 & 27.1 & \\
\hline & Medical/Nurse & 3.3 & 5.8 & \\
\hline & Researcher/Professor/Scientist & 29.7 & 16.6 & \\
\hline & Extension Officer & 0.0 & 1.4 & \\
\hline & Business/Merchant/Shopkeeper & 5.5 & 2.4 & \\
\hline & Housewife & 33.0 & 26.1 & \\
\hline & Others & 13.2 & 9.8 & \\
\hline \multirow[t]{6}{*}{7} & Education $^{\mathrm{a}}$ & & & 404 \\
\hline & Ph.D & 77.2 & 77.2 & \\
\hline & Masters & 21.8 & 19.8 & \\
\hline & Bachelors & 0.0 & 0.3 & \\
\hline & Diploma & 0.0 & 0.3 & \\
\hline & Others & 1.0 & 2.3 & \\
\hline 8 & Year of joining the organisation ${ }^{b}$ & 1981 & 1982 & 404 \\
\hline 9 & Year of obtaining highest degree* $b$ & 1983 & 1986 & 404 \\
\hline 10 & Degree from developed countries ${ }^{a}$ & 6.9 & 5.3 & 404 \\
\hline 11 & $\begin{array}{l}\text { Years spent outside India for higher } \\
\text { education } \mathrm{b}\end{array}$ & 0.53 & 0.32 & 404 \\
\hline 12 & Years spent in developed country ${ }^{b}$ & 0.6 & 0.4 & 404 \\
\hline
\end{tabular}

$* \mathrm{p}<.1, * * \mathrm{p}<.05, * * * \mathrm{p}<.01$.

a. In percentage, tested with Chi-square.

b. Results of t-test. 
Table 2

Professional Activities

\begin{tabular}{|c|c|c|c|c|}
\hline No. & Variable & 1994 & 2000 & $N$ \\
\hline 1 & Professionals(Scientist/engineer) supervised ${ }^{\mathrm{b}}$ & 1.55 & 1.29 & 401 \\
\hline 2 & Technicians and fieldworkers supervised ${ }^{\mathrm{b}}$ & 3.14 & 1.93 & 402 \\
\hline 3 & Non-technical staff supervised $* *$ b & 1.33 & 0.70 & 402 \\
\hline 4 & $\underset{\mathrm{b}}{\mathrm{P} \text { rofessional(Scientist/engineer)collaborators } * * *}$ & 8.63 & 3.23 & 402 \\
\hline 5 & Technicians/field workers collaborators $* * *$ b & 4.99 & 1.73 & 402 \\
\hline 6 & Non-technical staff collaborators $* * * b$ & 4.59 & 0.38 & 401 \\
\hline 7 & Membership in professional association ${ }^{\mathrm{a}}$ & 83.7 & 88.4 & 401 \\
\hline 8 & Held office in professional association ${ }^{a}$ & 46.9 & 44.9 & 401 \\
\hline 9 & $\begin{array}{l}\text { Served on the editorial board of professional } \\
\text { journals }^{\mathrm{a}}\end{array}$ & 29.6 & 31.4 & 401 \\
\hline 10 & $\begin{array}{l}\text { Member of government committees or advisory } \\
\text { group***a }\end{array}$ & 23.5 & 53.5 & 401 \\
\hline 11 & Served as a consultant ${ }^{\mathrm{a}}$ & 56.1 & 67.0 & 401 \\
\hline 12 & Advisor to extension services ${ }^{a}$ & 55.1 & 52.5 & 401 \\
\hline 13 & Advisor to an $\mathrm{NGO}^{\mathrm{a}}$ & 28.9 & 28.4 & 401 \\
\hline 14 & Training courses attended ${ }^{a}$ & 67.3 & 68.0 & 401 \\
\hline 15 & Professional meetings attended ${ }^{\mathrm{b}}$ & 9.91 & 12.52 & 389 \\
\hline 16 & Professional advisor to NGOs ${ }^{\mathrm{a}}$ & 28.9 & 28.4 & 400 \\
\hline 17 & $\begin{array}{l}\text { Days away from organisation for professional } \\
\text { activities } b\end{array}$ & $\begin{array}{c}30.1 \\
9\end{array}$ & 22.15 & 388 \\
\hline 18 & Professional awards received ${ }^{a}$ & 25.5 & 22.5 & 398 \\
\hline
\end{tabular}

a. In percentage, tested with Chi-square.

b. Results of t-test. 
Table 3

Productivity

\begin{tabular}{|c|c|c|c|c|}
\hline No. & Variable & 1994 & 2000 & $N$ \\
\hline 1 & Hours worked per week ${ }^{b}$ & 51.61 & 49.96 & 399 \\
\hline 2 & Hours devoted to research per week ${ }^{b}$ & 30.93 & 30.93 & 398 \\
\hline 3 & Number of research projects***b & 3.79 & 7.20 & 401 \\
\hline 4 & Number of research projects directed* & 2.20 & 3.57 & 401 \\
\hline 5 & Articles in foreign journals ${ }^{\mathrm{b}}$ & 2.27 & 2.21 & 399 \\
\hline 6 & Articles in national journals ${ }^{b}$ & 5.24 & 4.90 & 398 \\
\hline 7 & Chapters in edited volumes & 0.70 & 0.86 & 398 \\
\hline 8 & Reports or Monographs produced ${ }^{b}$ & 3.30 & 3.79 & 392 \\
\hline 9 & Bulletins for extension ${ }^{b}$ & 1.31 & 1.10 & 400 \\
\hline 10 & $\begin{array}{l}\text { Papers presented at international } \\
\text { conferences/workshops/seminars }\end{array}$ & 2.11 & 1.78 & 400 \\
\hline 11 & $\begin{array}{l}\text { Papers presented at national } \\
\text { conferences/workshops/seminars }\end{array}$ & 5.65 & 6.31 & 400 \\
\hline
\end{tabular}

${ }^{*} \mathrm{p}<.1, * * \mathrm{p}<.05, * * * \mathrm{p}<.01$.

a. In percentage, tested with Chi-square.

b. Results of t-test. 